\title{
Thermal and Cure Kinetics of Epoxy Molding Compounds Cured with Thermal Latency Accelerators
}

\author{
Chean-Cheng Su, Chien-Huan Wei, and Bo-Ching Li \\ Department of Chemical and Materials Engineering, National University of Kaohsiung, No. 700, Kaohsiung University Road, \\ Nan-Tzu District, Kaohsiung 811, Taiwan
}

Correspondence should be addressed to Chean-Cheng Su; ccsu@nuk.edu.tw

Received 30 November 2012; Accepted 14 January 2013

Academic Editor: Roham Rafiee

Copyright (c) 2013 Chean-Cheng Su et al. This is an open access article distributed under the Creative Commons Attribution License, which permits unrestricted use, distribution, and reproduction in any medium, provided the original work is properly cited.

\begin{abstract}
The cure kinetics and mechanisms of a biphenyl type epoxy molding compounds (EMCs) with thermal latency organophosphine accelerators were studied using differential scanning calorimetry (DSC). Although the use of triphenylphosphine-1,4-benzoquinone (TPP-BQ) and triphenylphosphine (TPP) catalysts in biphenyl type EMCs exhibited autocatalytic mechanisms, thermal latency was higher in the TPP-BQ catalyst in EMCs than in the TPP catalyst in EMCs. Analyses of thermal characteristics indicated that TPP-BQ is inactive at low temperatures. At high temperatures, however, TPP-BQ increases the curing rate of EMC in dynamic and isothermal curing experiments. The reaction of EMCs with the TPP-BQ latent catalyst also had a higher temperature sensitivity compared to the reaction of EMCs with TPP catalyst. In resin transfer molding, EMCs containing the TPP-BQ thermal latency accelerator are least active at a low temperature. Consequently, EMCs have a low melt viscosity before gelation, and the resins and filler are evenly mixed in the kneading process. Additionally, flowability is increased before the EMCs form a network structure in the molding process. The proposed kinetic model adequately describes curing behavior in EMCs cured with two different organophosphine catalysts up to the rubber state in the progress of curing.
\end{abstract}

\section{Introduction}

In IC design, semiconducting chips have become larger, while devices have become smaller. Highly reliable plasticencapsulated semiconductor packages are needed for advanced electronic devices. New epoxy molding compounds (EMCs) for encapsulating microelectronic devices are needed in the near future because halogen-containing flame retardants and antimony oxide flame retardant synergists, which are widely used in present-day molding compounds, may be environmentally hazardous. In typical green molding compounds, flame retardants (e.g., phosphorus-containing compounds, nitrogen-containing compounds, metal hydrate, metal oxide, inorganic filler, and resins with high $\mathrm{C} / \mathrm{H}$ ratios) have generally replaced the conventional halogen-containing flame retardants and antimony oxide flame retardants used in EMCs $[1,2]$. Notably, EMC with biphenyl resins and highly loaded fillers can retard flammability and is a green material. To produce reliable packaging materials for microelectronic devices, a highly loaded filter with specific characteristics is needed: high flame retardation, high thermal resistance, high moisture resistance, favorable mechanical properties, and a low thermal expansion coefficient of EMC $[3,4]$.

Catalysts are often used to accelerate curing in epoxy systems such as EMCs, epoxy prepreg, epoxy powder coating, and so forth, Choosing the appropriate type and amount of catalyst is important in epoxy formulations. In the literature [5-8], reports of catalysts for curing epoxy resin can be classified as Lewis bases and Lewis acids. Lewis bases contain an unshared pair of electrons in an outer orbit and tend to react with areas of low electron density. Their many applications include nucleophilic catalytic curing agents for epoxy homopolymerization; cocuring agents for primary amines, polyamides, and amidoamines; and catalysts for anhydrides. Tertiary amines and imidazoles are the most widely used nucleophilic catalysts. In contrast, Lewis acids, which have an empty outer orbit, tend to react with areas of high electron density. Complexation of boron trihalides with 
amines enhances the curing action. Reactivity depends on the selected halide and amine. Boron trifluoride monoethylamine is a typical catalyst.

EMCs typically include a curing accelerator (catalyst), which accelerates the curing of resin and increases the number of molding cycles for mass production. Storage stability, physical characteristics, and reliability of the encapsulated semiconductors diverge widely with the species of curing accelerator used. Capable of controlling initial polymerization, or curing, thermally latent catalysts are used in packaging. In EMCs, typical accelerators are imidazole [2, 9], amines [10-12], organophosphine $[1,10]$, urea derivatives $[13,14]$, or Lewis bases and their organic salts $[15,16]$. However, most accelerators tend to reduce the pot life or moldability of molding materials, owing to their ability to initiate reactions at extremely low temperatures. Therefore, an effective hardening accelerator must have a thermal latency that promotes the rapid curing of resins when heated to a particular temperature; in contrast, latent accelerators are inert at low temperatures $[1,17]$. Exactly how curing accelerators affect the physical and electrical characteristics of EMC have been thoroughly studied [16-19]. In these works, EMCs with triphenyl phosphine (TPP) have optimal physical properties and particularly good electrical properties under high humidity condition when cured, subsequently improving the reliability of the encapsulated semiconductors. However, the curing reaction of the EMC is significantly accelerated at a low temperature, in addition, a high melt viscosity during molding. EMC that contains TPP has a short pot life. Therefore, an improved organophosphine accelerator with thermally latent characteristics is urgently required for using in EMCs. Notably, the EMCs must have superior storage stability, latent reactivity, and low melting viscosity during molding.

The Lewis base catalyst, triphenylphosphine-1,4-benzoquinone (TPP-BQ), is the thermally latent catalyst used in the epoxy molding compounds, which can control initial polymerization or curing and are used in packaging $[1,20]$. A previous study found that TPP-BQ accelerated the reaction of EMCs more than TPP did at high temperatures; in addition, EMCs containing TPP-BQ were relatively inert at a low temperature [20]. In the TPP-BQ complex, the resonance of BQ increases the stability of the complex and reduces the activity of lone electron pairs. Nucleophilic attack by the organophosphine accelerators appears to open the epoxide, which is suppressed in the organophosphine acceleratorscured EMC at a low temperature. The molding compounds containing TPP-BQ exhibited excellent moldability and storage stability characteristics. Moreover, they were appropriate for transfer molding, owing to their excellent latent reactivity. Additionally, molding compounds containing TPP$\mathrm{BQ}$ had an extremely low melt viscosity before gelation. In low-viscosity green epoxy molding compounds, $4,4^{\prime}$ Diglycidyloxy-3, $3^{\prime}, 5,5^{\prime}$-tetramethyl biphenyl epoxy provides good adhesion, high toughness, and high filler loading. Because of its very low reaction rate, however, an EMC based on this biphenyl type epoxy is unsuitable for molding. This work synthesized a new organophosphine thermally latent accelerator, TPP-BQ, for use in high filler-loaded EMCs based
TABLE 1: Formulation of epoxy molding compounds.

\begin{tabular}{|c|c|c|}
\hline Composition & Raw materials & $\begin{array}{l}\text { Parts by } \\
\text { weight }\end{array}$ \\
\hline Epoxy & $\begin{array}{l}4,4^{\prime} \text {-diglycidyloxy- } 3,3^{\prime}, 5,5^{\prime}- \\
\text { tetramethyl biphenyl }\end{array}$ & 90 \\
\hline Br-epoxy & $\begin{array}{l}\text { Diglycidyl ether of brominated } \\
\text { bisphenol A }\end{array}$ & 10 \\
\hline Hardener & Phenol-aralkyl resin & 88 \\
\hline Accelerator & $\begin{array}{l}\text { Triphenylphosphine (TPP) or } \\
\text { triphenylphosphine-1,4-benzoquinone } \\
\text { (TPP-BQ) }\end{array}$ & 3 \\
\hline Filler & Fused silica & 1510 \\
\hline $\begin{array}{l}\text { Coupling } \\
\text { agent }\end{array}$ & Glycidoxypropyltrimethoxysilane & 7 \\
\hline Release agent & Ethyleneglycol ester of montanic acid & 7 \\
\hline Colorant & Carbon black & 4 \\
\hline
\end{tabular}

on biphenyl-type epoxy. The objective of this study was to characterize the reactivity and cure behavior of EMCs cured with thermal latency catalysts, TPP-BQ, and TPP. A kinetic model was used to show how a thermal latency catalyst affects curing in an EMC.

\section{Experimental}

2.1. Materials and Sample Preparation. Table 1 presents the formulation of the EMC. The epoxy resins used in the experiments were $4,4^{\prime}$-diglycidyloxy-3,3',5,5' -tetramethyl biphenyl (JER Co., YX-4000H, EW = $192 \mathrm{~g} / \mathrm{eq}$ ) and diglycidyl ether of brominated bisphenol A (Sumitomo Co., ESB 400). The hardener was phenol-aralkyl resin (Mitsui Chemical Inc., XLC-2L, OH EW = $175 \mathrm{~g} / \mathrm{eq})$. Scheme 1 shows the chemical structure of the epoxy and the hardener.

The TPP catalyst was obtained from Hooko Co. The TPP-BQ catalyst was synthesized by the authors and was identified using Fourier transform infrared spectroscopy (FTIR) and nuclear magnetic resonance (NMR) [20]. The chemical structure of the catalysts is described in Scheme 2.

The filler was fused silica with a mean particle size $\left(D_{50}\right)$ of $20 \mu \mathrm{m}$ (Tatsumori Co.). The coupling agent was glycidoxypropyltrimethoxysilane (Shin-Etsu Chemical Co.). The release agent was ethylene glycol ester of montanic acid (Hoechst Co.). The colorant was carbon black (Cabot Co., CM 800).

The materials were weighed out in the ratios given in Table 1 and thoroughly kneaded using a two-roll mill with the cold roller operated at $15^{\circ} \mathrm{C}$ and the hot roller operated at $120^{\circ} \mathrm{C}$. After mixing, EMC was cooled and pulverized. Each sample was then stored in a refrigerator at $4^{\circ} \mathrm{C}$.

2.2. Instruments. Calorimetric measurements were made using a differential scanning calorimeter (DSC) (PerkinElmer DSC-7) equipped with an intracooler. Isothermal and dynamic-heating experiments were performed at a $50 \mathrm{~mL} / \mathrm{min}$ nitrogen flow. In dynamic curing, the sample was 
<smiles>Cc1cc(-c2cc(C)c(OCC3CO3)c(C)c2)cc(C)c1OCC1CO1</smiles>

(a)

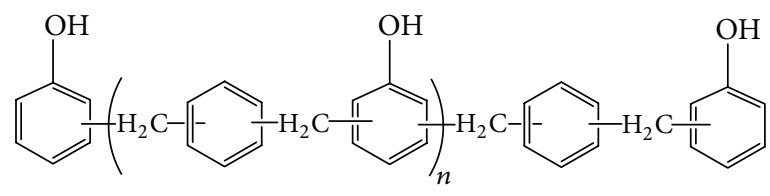

(b)

Scheme 1: The chemical structure of the (a) $4,4^{\prime}$-diglycidyloxy$3,3^{\prime}, 5,5^{\prime}$-tetramethyl biphenyl epoxy and (b) phenol-aralkyl resin.

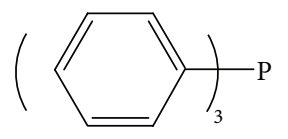

(a)

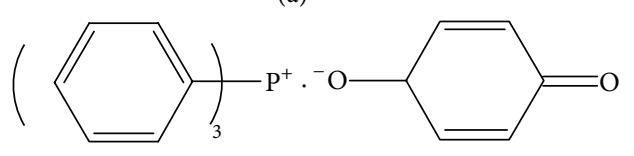

(b)

Scheme 2: The chemical structure of the (a) TPP and (b) TPP-BQ.

heated at a rate of $10^{\circ} \mathrm{C} / \mathrm{min}$ from $0^{\circ} \mathrm{C}$ to $250^{\circ} \mathrm{C}$. The isothermal curing reaction was performed at five temperatures $\left(130,150,165,175\right.$, and $\left.185^{\circ} \mathrm{C}\right)$. The reaction was considered complete when the isothermal DSC thermogram stabilized at the baseline level, which generally required approximately $1 \mathrm{~h}$. At the end of the reaction, the total area under the exotherm calculated according to the extrapolated baseline was used to calculate the isothermal heat of curing, $\Delta H_{\mathrm{Io}}\left(\mathrm{Jg}^{-1}\right)$. After the curing reaction was completed in the calorimeter, the sample was cooled to $40^{\circ} \mathrm{C}$. After curing, the samples were scanned at $10^{\circ} \mathrm{C} / \mathrm{min}$ from $40^{\circ} \mathrm{C}$ to $250^{\circ} \mathrm{C}$ to measure residual heat from the reaction, $\Delta H_{R}\left(\mathrm{Jg}^{-1}\right)$. The total heat of curing $\left(\Delta H_{T}\right)$ was calculated by summing the isothermal heat $\left(\Delta H_{\mathrm{Io}}\right)$ and the residual heat $\left(\Delta H_{R}\right)$ from the reactions. The isothermal conversion at time $t$ was defined as $\alpha_{I}(t)=\Delta H_{I}(t) / \Delta H_{T}$. The obtained $T_{g}$ values were taken as the temperatures of the onset of glass transition (at which the specific heat changed) in the DSC thermograms.

Morphology studies of the cured epoxy molding compounds were performed by scanning electron microscope (Hitachi S-4800 field-emission SEM). The fracture samples were polished and coated with gold by vapor deposition using a vacuum sputter.

2.3. Kinetic Analysis. A general equation for the autocatalytic cure reactions of many epoxy systems is as follows [21-25]:

$$
r=\frac{d \alpha}{d t}=\left(k_{1}+k_{2} \alpha^{m}\right)(1-\alpha)^{n}
$$

where $\alpha$ is the extent of conversion, $r$ is the rate of the reaction, $k_{1}$ and $k_{2}$ are the apparent rate constants, and $m$ and $n$ are the kinetic exponents of the reactions. The kinetic constants $k_{1}$ and $k_{2}$ are assumed to be in Arrhenius form [22-24, 26]:

$$
k_{i}=A_{i} \exp \left(-\frac{E_{a i}}{R T}\right)
$$

where $A_{i}$ is the preexponential constant, $E_{a i}$ is the activation energy, $R$ is the gas constant, and $T$ is the absolute temperature. The $\ln k_{i}$ can be plotted versus $1 / T$, and the activation energies are obtained in the equation. Equation (1) reveals that constant $k_{1}$ can be calculated from an initial reaction rate in which $\alpha$ approximates 0 . Additionally, (1) provides an initial estimate of the reaction order $n$ by performing the following modification:

$$
\ln \left(\frac{d \alpha}{d t}\right)=\ln \left(k_{1}+k_{2} \alpha^{m}\right)+n \ln (1-\alpha) .
$$

Except for the initial region, a plot of $\ln (d \alpha / d t)$ versus $\ln (1-$ $\alpha$ ) is expected to be linear and to have a slope of $n$. Further rearrangement of (1) gives

$$
\ln \left[\frac{d \alpha / d t}{(1-\alpha)^{n}}-k_{1}\right]=\ln k_{2}+m \ln \alpha .
$$

The first term in (4) can be determined from the previously estimated values for $k_{1}$ and $n$. A plot of the lefthand term in (4) versus $\ln (\alpha)$ is expected to yield a straight line. The slope and intercept can then be used to estimate the reaction order $m$ and the autocatalytic kinetic constant $k_{2}$, respectively. The described procedure is applicable for obtaining the preliminary kinetic parameters from the first trial. However, an iterative procedure is required to yield more values. Equation (4) can also be reformulated as

$$
\ln \left(\frac{d \alpha}{d t}\right)-\ln \left(k_{1}+k_{2} \alpha^{m}\right)=n \ln (1-\alpha),
$$

where $k_{2}, m$, and $n$ are estimated according to the stated procedures; the left-hand terms in (5) can be plotted against $\ln (1-\alpha)$; and a new value of the reaction order $n$ is checked against the one obtained earlier. The same iterative procedure can be repeated until the values of $m$ and $n$ converge to within a deviation of $1 \%$.

\section{Result and Discussion}

3.1. Analyzing Curing kinetics for EMCs with Thermal Latency Catalyst. After the EMCs with TPP and TPP-BQ catalysts were cured at isothermal temperatures of 130, 150, 165, 175 , and $185^{\circ} \mathrm{C}$, the above models were used for kinetic analysis. Figures 1 and 2 plot the curing rate curves for EMCs catalyzed by TPP-BQ and TPP, respectively, at five isothermal temperatures. Figure 1 shows that the curves are distinctly autocatalytic with the maximum rates occurring $3.0,1.9,1.2,1.0$, and $0.8 \mathrm{~min}$ after the start of the reaction at isothermal reaction temperatures of $130,150,165,175$, 


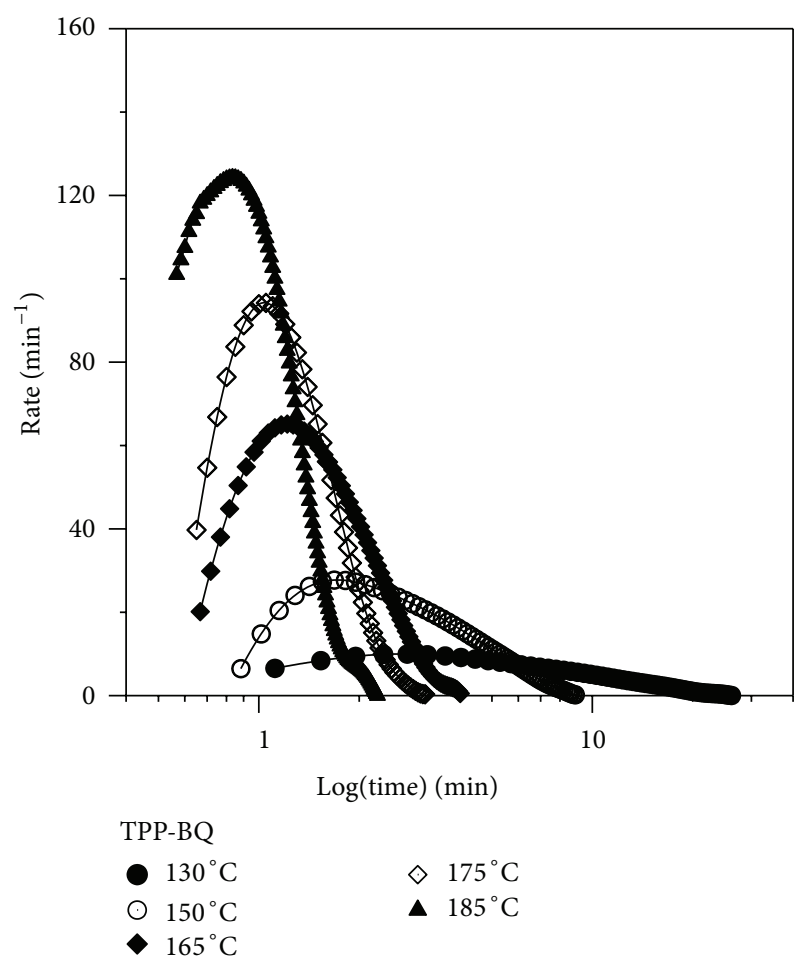

FIGURE 1: Plots of the reaction rate versus time for TPP-BQ-cured EMCs at isothermal temperatures.

and $185^{\circ} \mathrm{C}$, respectively. Figure 2 clearly shows that these rate curves are autocatalytic. The maximum rates were observed at $3.0,2.2,1.9,1.8$, and $1.7 \mathrm{~min}$ after the start of the reaction at isothermal reaction temperatures of $130,150,165,175$, and $185^{\circ} \mathrm{C}$, respectively. The result shown in these figures demonstrates that the mechanism of the TPP-BQ-cured EMCs and that of TPP-cured EMCs has the same autocatalytic nature. However, the reaction rate of the TPP-BQ-cured EMC is clearly enhanced at high temperature and restrained at low temperature since the maximum rate increases with reaction temperature in the molding compounds. The epoxy reaction rate revealed a similar effect in the epoxy molding compounds with TPP catalyst. Figures 3(a) and 3(b) show the times of the maximum rate and curing time, respectively, in the epoxy molding compounds cured with organophosphine accelerators. In the epoxy molding compounds cured with catalysis with organophosphine accelerators, the times of the maximum rate and curing time depended on both the reaction temperature and the organophosphine accelerator type. Figure 3(a) indicates that EMCs catalyzed by TPP had a shorter time of the maximum rate than that of EMCs catalyzed by TPP-BQ at a low temperature $\left(130^{\circ} \mathrm{C}\right)$. Conversely, EMCs catalyzed by TPP-BQ had a shorter time of the maximum rate than that of EMCs catalyzed by TPP at high temperatures $\left(150,165,175\right.$, and $\left.185^{\circ} \mathrm{C}\right)$. The same change was also observed in the curing time in EMCs catalyzed by organophosphine accelerators (Figure 3(b)). At low temperature $\left(130^{\circ} \mathrm{C}\right)$, the curing rate of EMCs containing TPP exceeded that of EMCs containing TPP-BQ; at high temperatures $\left(150,165,175\right.$, and $\left.185^{\circ} \mathrm{C}\right)$, however, EMCs

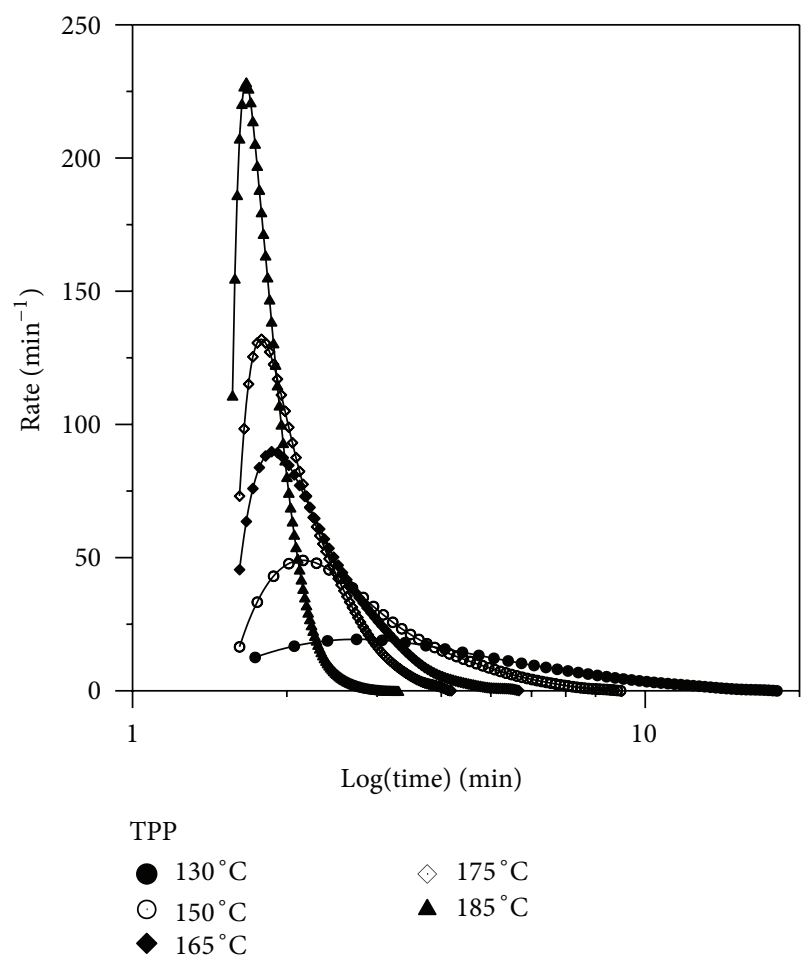

FIGURE 2: Plots of the reaction rate versus time for TPP-cured EMCs at isothermal temperatures.

containing TPP-BQ are cured at a higher rate compared to EMCs containing TPP. The EMCs catalyzed by TPP-BQ accelerator also had a rapid rate of curing at the molding temperatures used specifically for IC encapsulation $(T=$ $\left.175-185^{\circ} \mathrm{C}\right)$. These findings indicate that TPP is better than TPP-BQ as a catalyst for curing EMCs at low temperatures. At high temperatures, however, the acceleration in reaction time was larger in EMCS cured with TPP-BQ than in EMCS cured with TPP, and EMCs containing TPP-BQ were relatively inert at a low temperature. Notably, the general biphenyl EMC transfer molding temperatures used for IC encapsulation range from 175 to $185^{\circ} \mathrm{C}$. During molding, EMCs containing TPP-BQ are least active before the temperature reaches the molding temperature. The experimental results indicate that TPP-BQ is superior to TPP as a latency accelerator in biphenyl type EMCs.

Table 2 presents the mean residual heat of reaction $\left(\Delta H_{R}\right)$, isothermal heat of reaction $\left(\Delta H_{\mathrm{Io}}\right)$, total heat of curing $\left(\Delta H_{T}\right)$, and isothermal conversion $\left(\alpha_{I}\right)$. Note that the heat from reactions in the EMCs was calculated based on the net weight of the biphenyl/phenol-aralkyl resin in the molding compounds without considering the weight of fillers in the EMCs. In this work, the total heats of curing $\left(\Delta H_{\text {Io }}+\Delta H_{R}\right)$ were independent of the organophosphine accelerator type. The mean value was $184 \mathrm{Jg}^{-1}$. At a $130^{\circ} \mathrm{C}$ curing temperature, the table also shows that the isothermal conversions $\left(\alpha_{I}\right)$ were 92.9 and $93.4 \%$ for EMCs containing TPP and TPP$\mathrm{BQ}$, respectively, which indicated that the reactions were incomplete at a low temperature. However, the isothermal conversions $\left(\alpha_{I}\right)$ were $100 \%$ when the EMCs were completely 
TABLE 2: Heats of reaction of epoxy molding compounds catalyst by TPP and TPP-BQ.

\begin{tabular}{lccccc}
\hline Accelerators & $T\left({ }^{\circ} \mathrm{C}\right)$ & $\begin{array}{c}\Delta H_{\mathrm{Io}} \\
\left(\mathrm{Jg}^{-1}\right)\end{array}$ & $\begin{array}{c}\Delta H_{R} \\
\left(\mathrm{Jg}^{-1}\right)\end{array}$ & $\begin{array}{c}\Delta H_{T} \\
\left(\mathrm{Jg}^{-1}\right)\end{array}$ & $\alpha_{\mathrm{I}}(\%)$ \\
\hline \multirow{4}{*}{ TPP-BQ } & 130 & 170 & 12 & 182 & 93.4 \\
& 150 & 184 & 0 & 184 & 100 \\
& 165 & 183 & 0 & 183 & 100 \\
& 175 & 185 & 0 & 185 & 100 \\
TPP & 185 & 186 & 0 & 186 & 100 \\
\hline \multirow{4}{*}{} & 130 & 171 & 13 & 184 & 92.9 \\
& 150 & 183 & 0 & 183 & 100 \\
& 165 & 184 & 0 & 184 & 100 \\
& 175 & 183 & 0 & 183 & 100 \\
& 185 & 185 & 0 & 185 & 100 \\
\hline
\end{tabular}

cured at high temperatures $\left(150-185^{\circ} \mathrm{C}\right)$. The table also shows that the ultimate conversion $\left(\alpha_{I}\right)$ for EMCs catalyzed by organophosphine accelerators increased from 93 to $100 \%$, as cure temperature increased from 130 to $185^{\circ} \mathrm{C}$, which indicate that the reactions would be expected to reach diffusion control (rubber state) regions at progressively higher conversions, as reaction temperatures increase. Furthermore, EMCs containing TPP and TPP-BQ accelerators not only had similar reaction rate curves, but they also had similar $\Delta H$ and $\alpha_{I}$, which suggests EMCs containing TPP and TPP-BQ accelerators have a similar reaction mechanism.

3.2. Autocatalytic Model Analysis. The molding compound data were then analyzed using the proposed autocatalytic mechanism. The kinetic parameters were determined using the above procedures. For the kinetic constants $k_{1}$ and $k_{2}$, two activation energies, $\Delta E_{1}$ and $\Delta E_{2}$, could be obtained by plotting $\ln k_{1}$ and $\ln k_{2}$, respectively, versus $1 / T$. Figure 4 shows the plots for $\ln k_{1}$ and $\ln k_{2}$ versus $1 / T$, from which the activation energies were determined for the EMCs. Table 3 lists the rate constants obtained after considerable iteration and graphic procedures. Reaction orders $m$ and $n$ approximated 0.5 and 1.4 , respectively, and did not substantially vary among EMCs with different organophosphine accelerators. For the TPP-BQ-catalysis EMCs, the $E_{a 1}$ and $E_{a 2}$ values obtained in this study were 15.2 and $11.6 \mathrm{~kJ} \mathrm{~mol}^{-1}$, respectively. In contrast, the $E_{a 1}$ and $E_{a 2}$ values obtained for the TPPcatalysis EMCs were 11.4 and $9.6 \mathrm{~kJ} \mathrm{~mol}^{-1}$, respectively. As activation energy increased, the temperature sensitivity of the reaction increased. Restated, for a large activation energy, a temperature increase of only a few degrees significantly increased $k$, subsequently increasing the reaction rate. In comparison to TPP catalyst-cured EMCs, TPP-BQ catalystcured EMCs had higher activation energies. Further, since the difference in $\Delta E_{a 1}\left(3.8 \mathrm{~kJ} \mathrm{~mol}^{-1}\right)$ between TPP-BQ catalystcured EMCs and TPP catalyst-cured EMCs was larger than the difference in $\Delta E_{a 2}\left(2 \mathrm{~kJ} \mathrm{~mol}^{-1}\right)$ between TPP-BQ catalystcured EMCs and TPP catalyst-cured EMCs, the increased reaction rate might be associated with $k_{1}$. Since $k_{1}$ governs the early stage-autocatalytic reaction and since $k_{2}$ affects

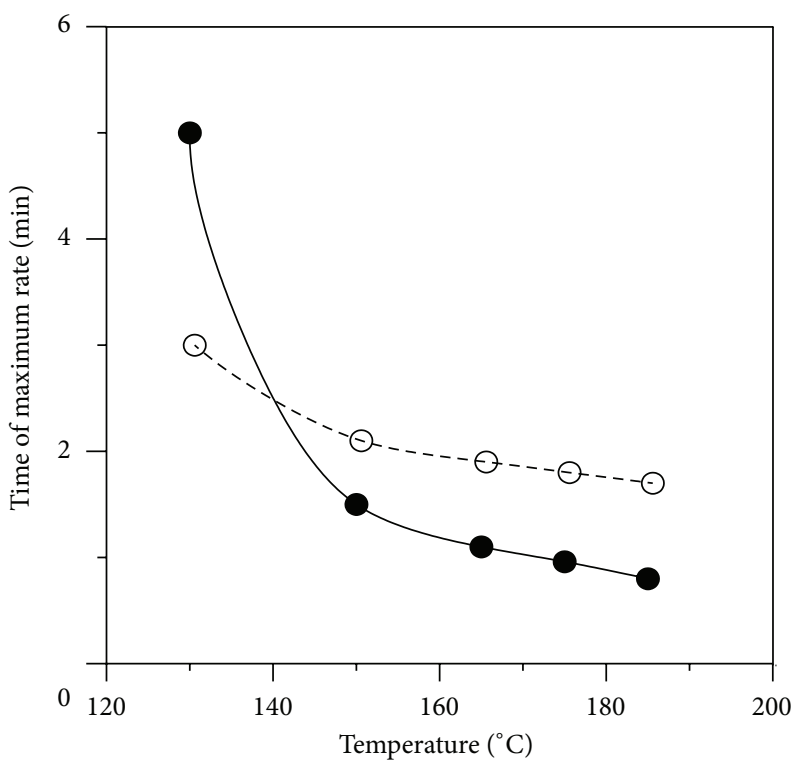

(a)

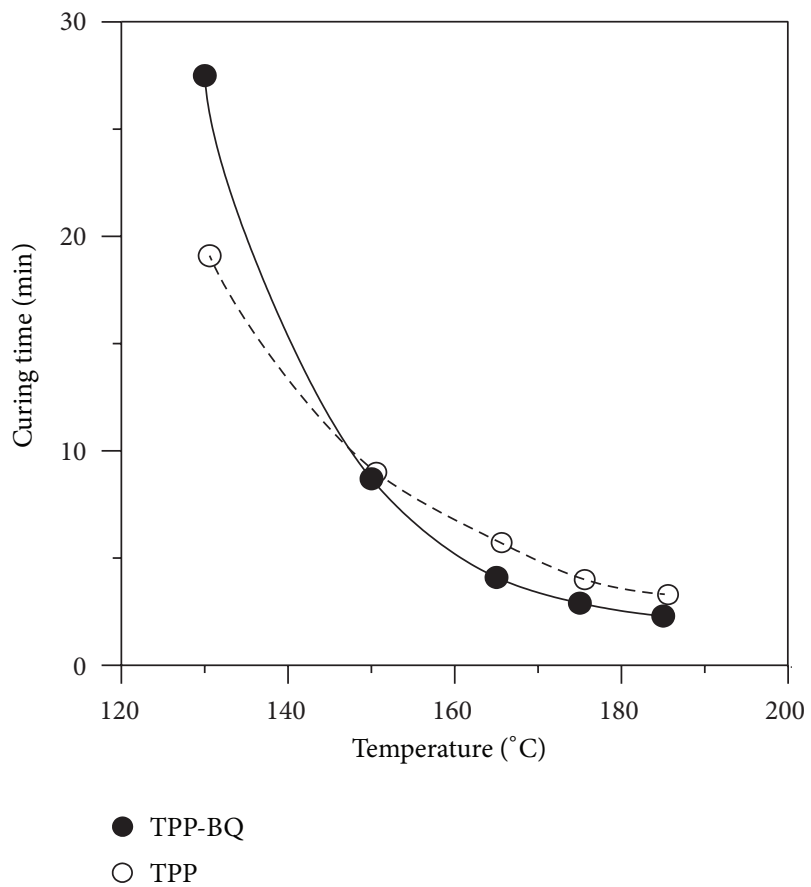

(b)

FIGURE 3: Curing times of organophosphine accelerators-cured EMCs at isothermal temperatures: (a) times of the maximum rate and (b) curing times.

the reaction after the initial autocatalytic stage, the rate of increase at high temperatures in EMCs with TPP-BQ catalyst should be expected to accelerate in the initial stage of the reaction [26].

The autocatalytic kinetic model and the rate constants obtained (listed in Table 3) were used to calculate empirical curves of conversion versus time for the organophosphine accelerator-cured EMCs at all five isothermal cure temperatures. Figures 5 and 6 show that the empirical conversion 
TABLE 3: Kinetic parameters for epoxy molding compounds catalyst by TPP and TPP-BQ.

\begin{tabular}{|c|c|c|c|c|c|c|c|c|c|}
\hline Accelerator & $T\left({ }^{\circ} \mathrm{C}\right)$ & $m$ & $n$ & $\begin{array}{c}k_{1} \\
\left(\min ^{-1}\right)\end{array}$ & $\begin{array}{c}k_{2} \\
\left(\min ^{-1}\right)\end{array}$ & $\begin{array}{c}E_{a 1} \\
\left(\mathrm{~kJ} \mathrm{~mol}^{-1}\right)\end{array}$ & $\begin{array}{c}E_{a 2} \\
\left(\mathrm{~kJ} \mathrm{~mol}^{-1}\right)\end{array}$ & $\ln A_{1}$ & $\ln A_{2}$ \\
\hline \multirow{5}{*}{ TPP-BQ } & 130 & 0.4 & 1.3 & 6.6 & 12.8 & \multirow{5}{*}{18.3} & \multirow{5}{*}{11.6} & \multirow{5}{*}{16.5} & \multirow{5}{*}{13.3} \\
\hline & 150 & 0.4 & 1.4 & 6.5 & 61.7 & & & & \\
\hline & 165 & 0.5 & 1.0 & 20.2 & 129.4 & & & & \\
\hline & 175 & 0.6 & 1.0 & 39.8 & 200.5 & & & & \\
\hline & 185 & 1.3 & 1.1 & 114.8 & 330.8 & & & & \\
\hline \multirow{5}{*}{ TPP } & 130 & 0.5 & 1.3 & 12.6 & 31.6 & \multirow{5}{*}{12.6} & \multirow{5}{*}{9.6} & \multirow{5}{*}{12.9} & \multirow{5}{*}{12.3} \\
\hline & 150 & 0.5 & 1.3 & 16.5 & 102.9 & & & & \\
\hline & 165 & 0.6 & 1.4 & 45.5 & 189.3 & & & & \\
\hline & 175 & 0.6 & 1.5 & 73.1 & 291.0 & & & & \\
\hline & 185 & 0.5 & 1.5 & 110.9 & 476.9 & & & & \\
\hline
\end{tabular}

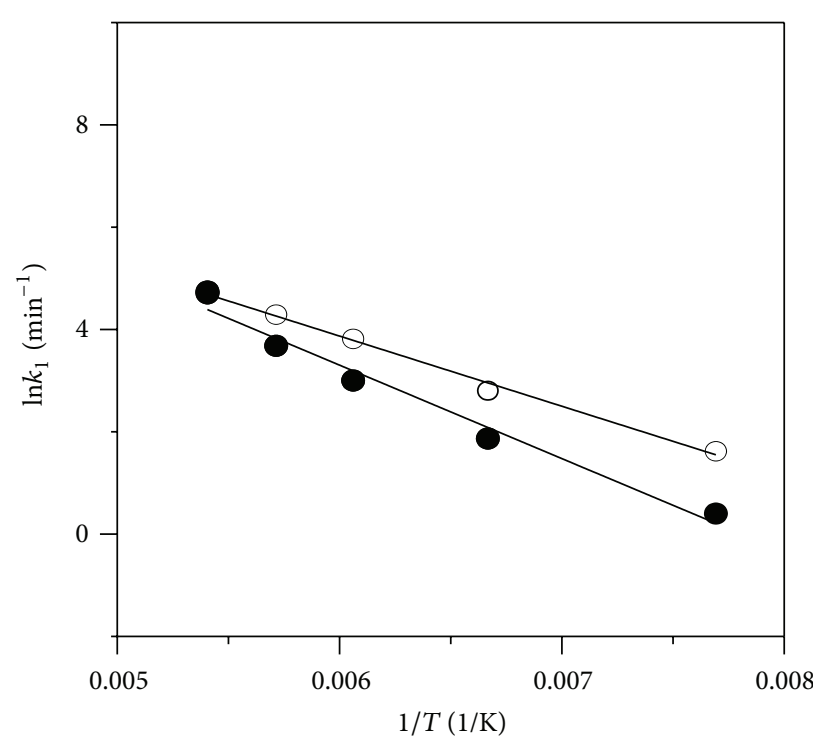

$1 / T(1 / \mathrm{K})$

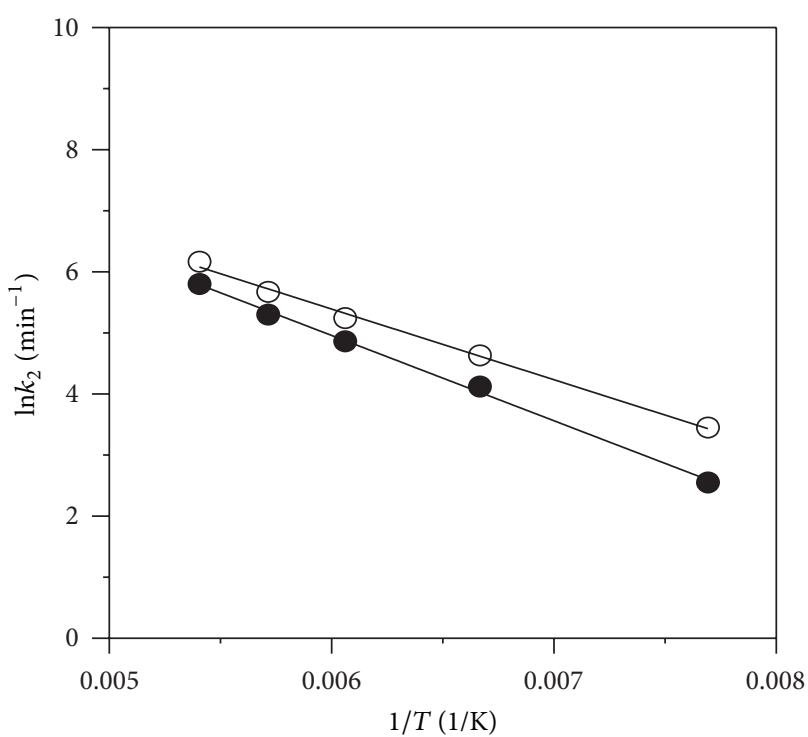

O TPP

- TPP-BQ

(a)

(b)

FIGURE 4: Kinetic analysis for organophosphine accelerators-cured EMCs in an autocatalysed reaction: (a) plots of $\ln k_{1}$ against $1 / T$ and (b) plots of $\ln k_{2}$ against $1 / T$, respectively.

curves fit the experimental data quite well until the cure reactions progress to the rubber state for TPP-BQ-cured EMCs and TPP-cured EMCs. Epoxy resins are thermosets whose individual chains have been chemically linked by covalent bonds during isothermal reaction. Once formed, these crosslinked networks resist heat softening and creep. Generally, a rubber-like state may be defined as an amorphous and crosslinked polymer above its glass transition temperature $\left(T_{g}\right)$. Following cross linking, flow of one molecule past another is suppressed in organophosphine accelerator-cured EMCs in the rubber state. In the work, a similar $T_{g}$ value $\left(120^{\circ} \mathrm{C}\right)$ was obtained in fully cured TPP-BQ-cured EMCs and TPPcured EMCs. Apparently, the model satisfactorily describes the kinetic well. However, diffusion control in the rubber state affects the predictive accuracy of the model. This indicates that the cure kinetics for organophosphine accelerator-cured EMCs in the later stage are indeed subject to diffusion control in the rubber state. In the organophosphine acceleratorcured EMCs, the predictability of the model at high cure temperatures is better than that at low cure temperatures.

\subsection{Comparison of TPP-BQ-Cured EMCs with TPP-Cured} EMCs. Figures 7 and 8 show the rate versus conversion curves for organophosphine accelerator-cured EMCs at five isothermal cure temperatures $\left(130,150,165,175\right.$, and $\left.185^{\circ} \mathrm{C}\right)$. Figure 7 shows the similar trends in cure reaction rates observed in TPP-BQ-cured EMCs at five cure temperatures. The maximum rates approximated $33 \%$ and $17 \%$ of the 


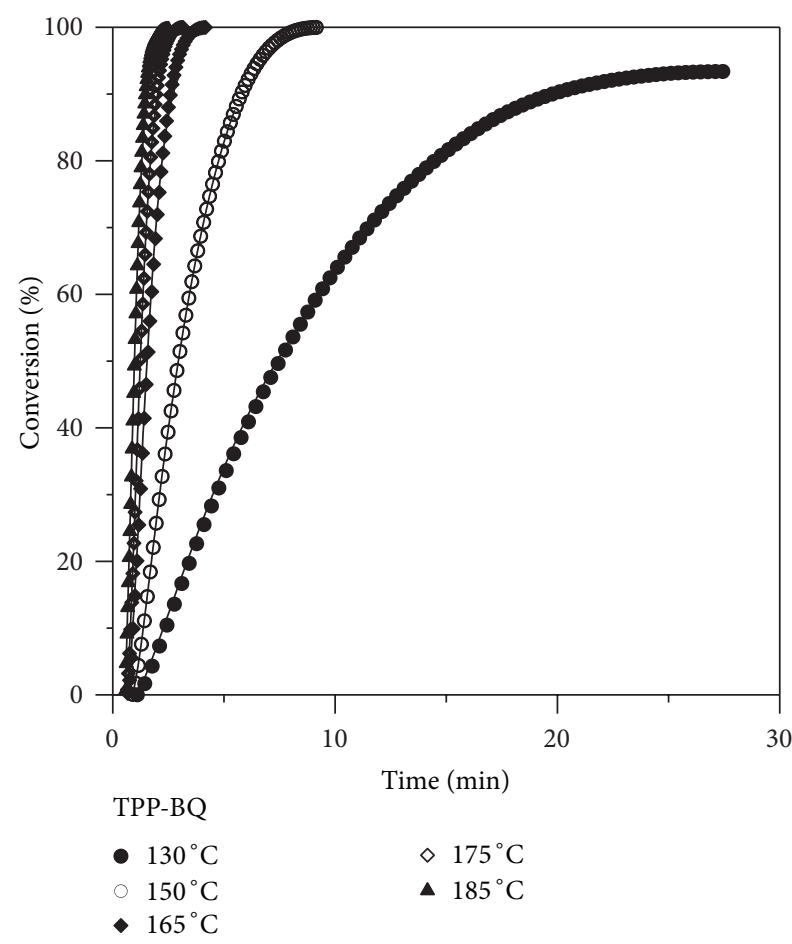

FIGURE 5: Comparison between the autocatalytic model and data for TPP-BQ-cured EMCs at isothermal temperatures.

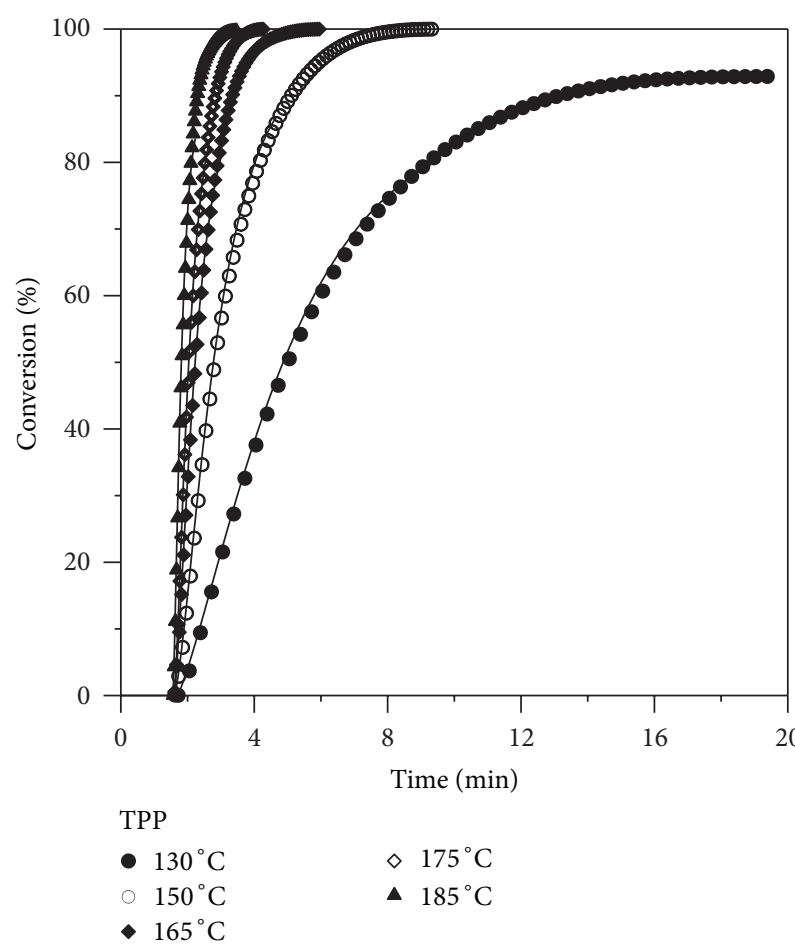

FIGURE 6: Comparison between the autocatalytic model and data for TPP-cured EMCs at isothermal temperatures.

conversion at high temperatures $\left(165,175\right.$, and $\left.185^{\circ} \mathrm{C}\right)$ and at low temperatures $\left(130\right.$ and $\left.150^{\circ} \mathrm{C}\right)$, respectively. In contrast, the trends in cure reaction rates of TPP-cured EMCs are similar at five cure temperatures, and the maximum rate approximated $20 \%$ and $10 \%$ of the conversion at high temperatures $\left(165,175\right.$, and $\left.185^{\circ} \mathrm{C}\right)$ and at low temperatures $(130$

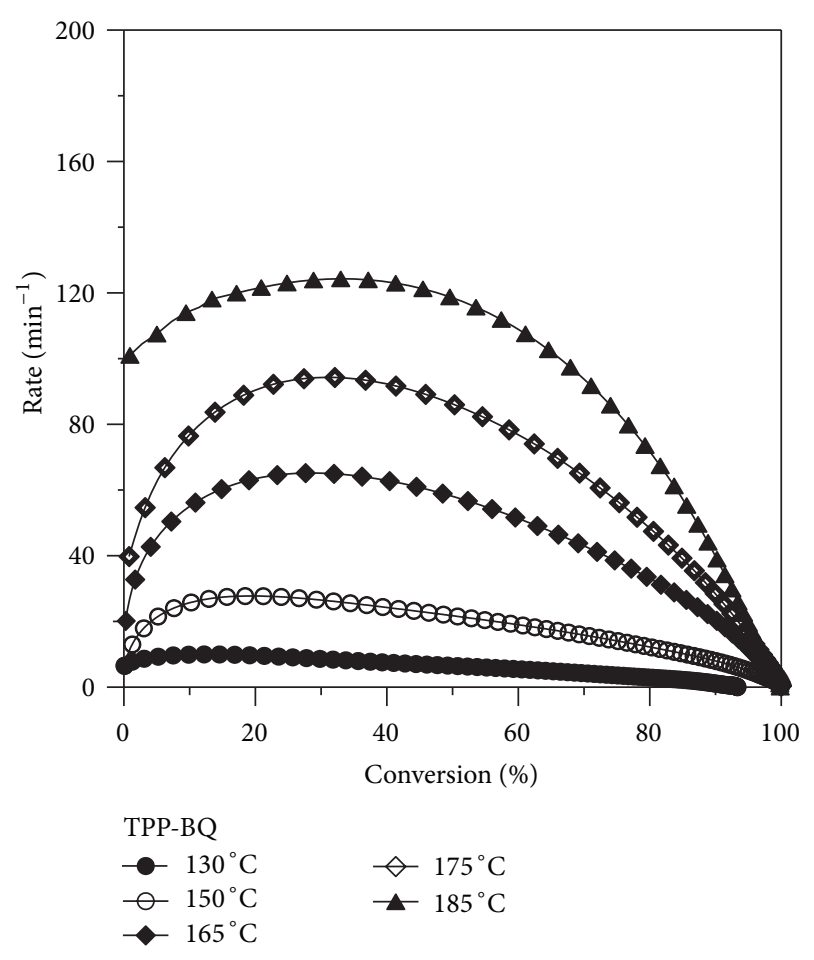

FIGURE 7: Plots of the reaction rate versus conversion for TPP-BQcured EMCs at isothermal temperatures.

and $150^{\circ} \mathrm{C}$ ), respectively (Figure 8 ). In TPP-BQ acceleratorcured biphenyl EMCs, the reaction of the biphenyl/phenolaralkyl resin at higher conversions still maintained a high rate of progress in the cure reaction. In contrast, the reaction rate of TPP accelerator-cured EMCs was high in the early stage and low in the later stage. After 70\% conversion, TPP-BQcured EMCs had a higher rate than TPP accelerator-cured EMCs did at the five cure temperatures shown in the figures. In resin transfer molding, EMC flowed through the molding part until the compound was transformed into gel. If the curing rate of EMC was too fast, the melting EMC would have increased the viscosity and decreased the flowability in the mold. Both viscosity and flowability are generally related to the degree of reaction of EMC during molding. In microelectronic packaging, the acceleration of the reaction of EMC containing TPP-BQ is weak at low temperatures but strong at high temperatures during thermal latency curing. The experimental results suggest that the TPP-BQ accelerator is an ideal thermal latency accelerator for curing EMCs.

3.4. Morphology of EMCs with High Filler Content. The EMCs with high filler contents are accelerated by organophosphine accelerators, TPP-BQ and TPP, which provide excellent flowability in the molding process. In the molding process, melting EMCs with high flowability easily fill the whole mould before hardening. Figures 9(a) and 9(b) show the morphology of the fractured surface of EMCs with $88 \mathrm{wt} \%$ content of silica accelerated by TPP-BQ and TPP accelerator, respectively, and cured at $175^{\circ} \mathrm{C}$. In Figure 9(a), the spherulic silca of varying sizes is well distributed and packed closely 


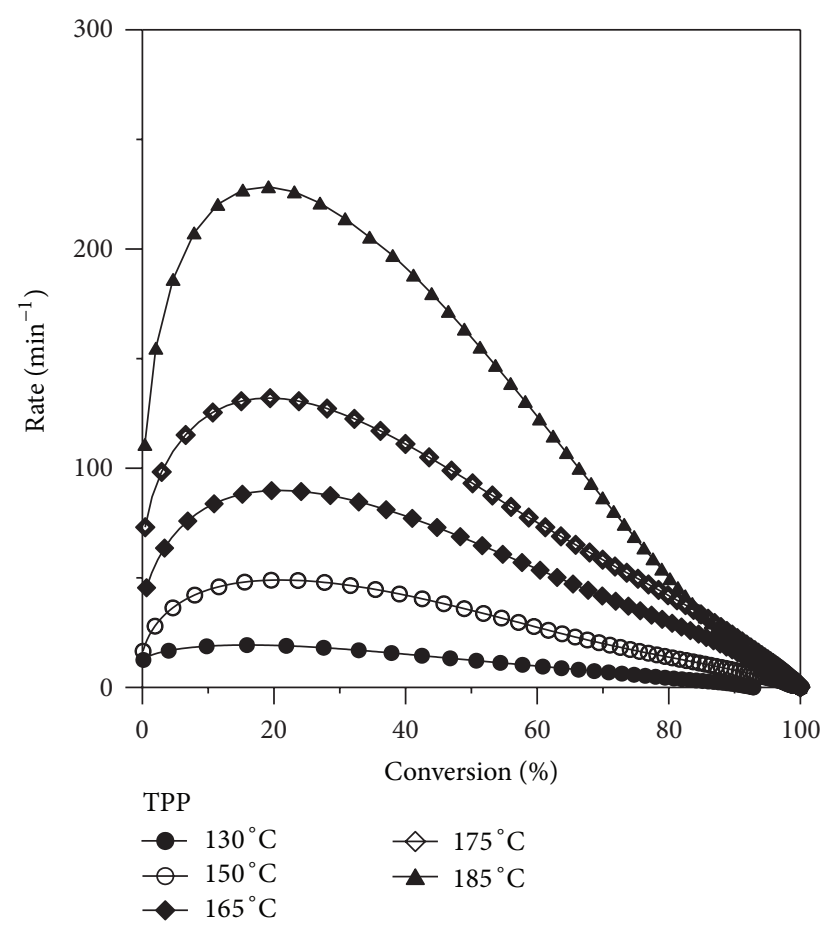

FIGURE 8: Plots of the reaction rate versus conversion for TPP-cured EMCs at isothermal temperatures.

on the fractured surface of the EMC in the cured sample. Because TPP-BQ-cured EMCs have a low melt viscosity before gelation as well as least active at low temperatures, the organic matrixes and filler are easily and well mixed in the kneading process; in addition, the flowability of EMC is increased in the molding process. In contrast, the silica is less evenly distributed and is loosely packed in the fractured surface of the TPP-cured EMC shown in Figure 9(b). The silica is not well mixed in the TPP-cured EMC because the EMC had a high reaction rate and a high viscosity in the kneading process.

\section{Conclusions}

In isothermal curing, TPP is a more rapid catalyst compared to TPP-BQ for curing EMCs at low temperatures. However, TPP-BQ accelerated the reaction of EMCs more than TPP did at high temperatures, and EMCs containing TPP-BQ were relatively inert at a low temperature. An autocatalytic mechanism was observed for organophosphine acceleratorcured EMCs. Kinetic parameters for the EMCs with TPPBQ and TPP accelerator were obtained, and the proposed kinetic model accurately described the cure behavior of organophosphine accelerator-cured EMCs up to the rubber state. Although the reaction mechanism for both TPP-BQcured EMCs and TPP-cured EMCs was similar, thermal latency was superior in the TPP-BQ-cured EMCs. The model showed that the increased temperature sensitivity resulted from the larger activation energy in EMCs with TPP-BQ accelerator. Based on the observations in this study, the rate increase at high temperatures in EMCs with TPP-BQ catalyst

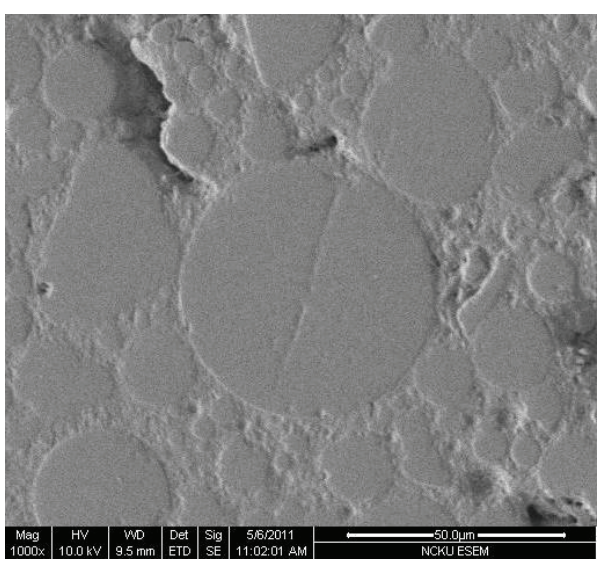

(a)

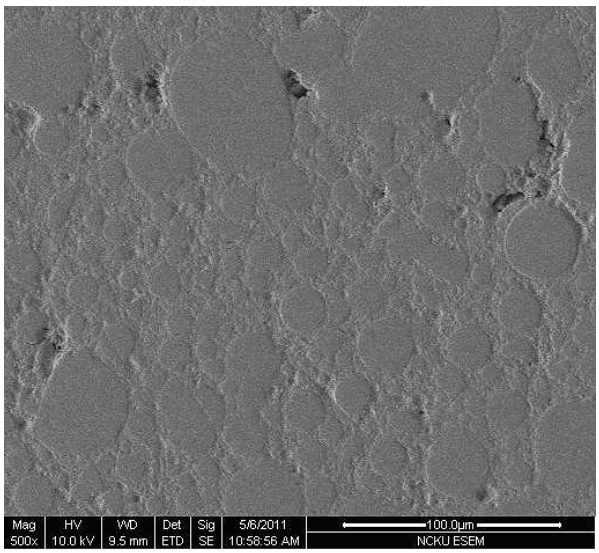

(b)

FIGURE 9: Morphology of organophosphine accelerators-cured epoxy molding compounds: (a) TPP-BQ-cured EMC and (b) TPPcured EMC, respectively.

should be pronounced in the initial stage of the reaction. Furthermore, in TPP-BQ accelerator-cured biphenyl EMCs, the reaction of the EMC at high conversions remained high as the cure reaction progressed during the EMC transfer molding process. In microelectronic packaging, the acceleration of the reaction of EMC containing thermal latency TPP-BQ accelerator correlates positively with temperature. This suggests that the TPP-BQ accelerator is an ideal thermal latency accelerator for curing EMCs.

\section{Acknowledgments}

This study is sponsored by the National Science Council of the Taiwan for financially supporting this research under Contract no. NSC 100-2221-E-390-006-MY2. The authors declare no competing financial interest.

\section{References}

[1] J. H. Ryu, K. S. Choi, and W. G. Kim, "Latent catalyst effects in halogen-free epoxy molding compounds for semiconductor encapsulation," Journal of Applied Polymer Science, vol. 96, no. 6, pp. 2287-2299, 2005. 
[2] G. H. Hsiue, Y. L. Liu, and H. H. Liao, "Flame-retardant epoxy resins: an approach from organic-inorganic hybrid nanocomposites," Journal of Polymer Science A, vol. 39, no. 37, pp. 986996, 2001.

[3] N. Kinjo, M. Ogata, K. Nishi, and A. Kaneda, "Epoxy molding compounds as encapsulation materials for microelectronic devices," Advanced Polymer Science, vol. 88, no. 1, pp. 1-48, 1989.

[4] Y. Nakamura, M. Yamaguchi, A. Tanaka, and M. Okubo, “Thermal shock test of integrated circuit packages sealed with epoxy moulding compounds filled with spherical silica particles," Polymer, vol. 34, no. 15, pp. 3220-3224, 1993.

[5] H. F. Mark, Encyclopedia of Polymer Science and Technology, John Wiley \& Sons, New York, NY, USA, 3rd edition, 2007.

[6] A. Romanchick and J. F. Geibel, "Synthesis of solid rubbermodified epoxy resins," Organic Coatings and Applied Polymer Science Processing, vol. 46, no. 2, pp. 410-415, 1982.

[7] A. M. Tomuta, X. Ramis, and F. Ferrando, "The use of dihydrazides as latent curing agents in diglycidyl ether of bisphenol A coatings," Progress in Organic Coatings, vol. 74, no. 1, pp. 5966, 2012.

[8] I. Glavchev, K. Petrova, and I. Devedjiev, "Determination of the rate of cure of epoxy resin/maleic anhydride/Lewis acids," Polymer Testing, vol. 21, no. 1, pp. 89-91, 2002.

[9] C. S. Wang and C. Kwag, "Cure kinetics of an epoxy-anhydrideimidazole resin system by isothermal DSC," Polymers and Polymer Composites, vol. 14, no. 5, pp. 445-454, 2006.

[10] Z. Ma and J. Gao, "Curing kinetics of o-cresol formaldehyde epoxy resin and succinic anhydride system catalyzed by tertiary amine," Journal of Physical Chemistry B, vol. 110, no. 25, pp. 12380-12383, 2006.

[11] T. Nakaya, M. Shimbo, and T. Takahama, "Effects of tertiary amine accelerators on curing of epoxide resins," Journal of Polymer Science B, vol. 24, no. 9, pp. 1931-1941, 1986.

[12] A. Srivastava, N. Pal, S. Agarwal, and J. S. P. Rai, "Kinetics and mechanism of esterification of epoxy resin with methacrylic acid in the presence of tertiary amines," Advances in Polymer Technology, vol. 24, no. 1, pp. 1-13, 2005.

[13] H. Niino, S. Noguchi, Y. Nakano, and S. Tazuke, "Aminimide as hardener/curing promotor for one part epoxy resin composition," Journal of Applied Polymer Science, vol. 27, no. 7, pp. 23612368, 1982.

[14] X. D. Liu, M. Kimura, A. Sudo, and T. Endo, "Accelerating effects of $\mathrm{N}$-aryl- $\mathrm{N}^{\prime}, \mathrm{N}^{\prime}$-dialkyl ureas on epoxy-dicyandiamide curing system," Journal of Polymer Science A, vol. 48, no. 23, pp. 52985305, 2010.

[15] P. N. Son and C. D. Weber, "Some aspects of monuronaccelerated dicyandiamide cure of epoxy resins," Journal of Applied Polymer Science, vol. 17, no. 5, pp. 1305-1313, 1973.

[16] M. Kobayashi, F. Sanda, and T. Endo, "Substituent effect of (triphenylphosphinemethylene)boranes on latent catalytic activity for polyaddition of bisphenol a diglycidyl ether with bisphenol a: model system of epoxy-novolac resin," Macromolecules, vol. 35, no. 2, pp. 346-348, 2002.

[17] S. Han, W. G. Kim, H. G. Yoon, and T. J. Moon, "Curing reaction of biphenyl epoxy resin with different phenolic functional hardeners," Journal of Polymer Science A, vol. 36, no. 5, pp. 773$783,1998$.

[18] W. G. Kim, J. Y. Lee, and K. Y. Park, "Curing reaction of o-cresol novolac epoxy resin according to hardener change," Journal of Polymer Science A, vol. 31, no. 3, pp. 633-639, 1993.
[19] M. Ogata, N. Kinjo, S. Eguchi, H. Hozoji, T. Kawata, and H. Sashima, "Effects of curing accelerators on physical properties of epoxy molding compound (EMC)," Journal of Applied Polymer Science, vol. 44, no. 10, pp. 1795-1805, 1992.

[20] C. C. Su, C. H. Wei, and C. C. Yang, "Elucidating how advanced organophosphine accelerators affect molding compounds," Industrial \& Engineering Chemistry, 2013.

[21] W. G. Kim and J. H. Ryu, "Physical properties of epoxy molding compound for semiconductor encapsulation according to the coupling treatment process change of silica," Journal of Applied Polymer Science, vol. 65, no. 10, pp. 1975-1982, 1997.

[22] C. C. Su and E. M. Woo, "Cure kinetics and morphology of amine-cured tetraglycidyl-4, $4^{\prime}$-diaminodiphenylmethane epoxy blends with poly(ether imide)," Polymer, vol. 36, no. 15, pp. 2883-2894, 1995.

[23] C. C. Su, Y. P. Huang, and E. M. Woo, "Curing kinetics and reaction-induced homogeneity in networks of poly(4vinyl phenol) and diglycidylether epoxide cured with amine," Polymer Engineering and Science, vol. 45, no. 1, pp. 1-10, 2005.

[24] C. C. Su and E. M. Woo, "Diffusion-controlled reaction mechanisms during cure in polycarbonate-modified epoxy networks," Journal of Polymer Science B, vol. 35, no. 13, pp. 2141-2150, 1997.

[25] K. C. Cole, J. J. Hechler, and D. Noël, "A new approach to modeling the cure kinetics of epoxy amine thermosetting resins. 2. Application to a typical system based on bis[4(diglycidylamino)phenyl]methane and bis(4-aminophenyl) sulfone," Macromolecules, vol. 24, no. 11, pp. 3098-3110, 1991.

[26] H. S. Fogler, Essentials of Chemical Reaction Engineering, Pearson Education, New York, NY, USA, 4th edition, 2011. 

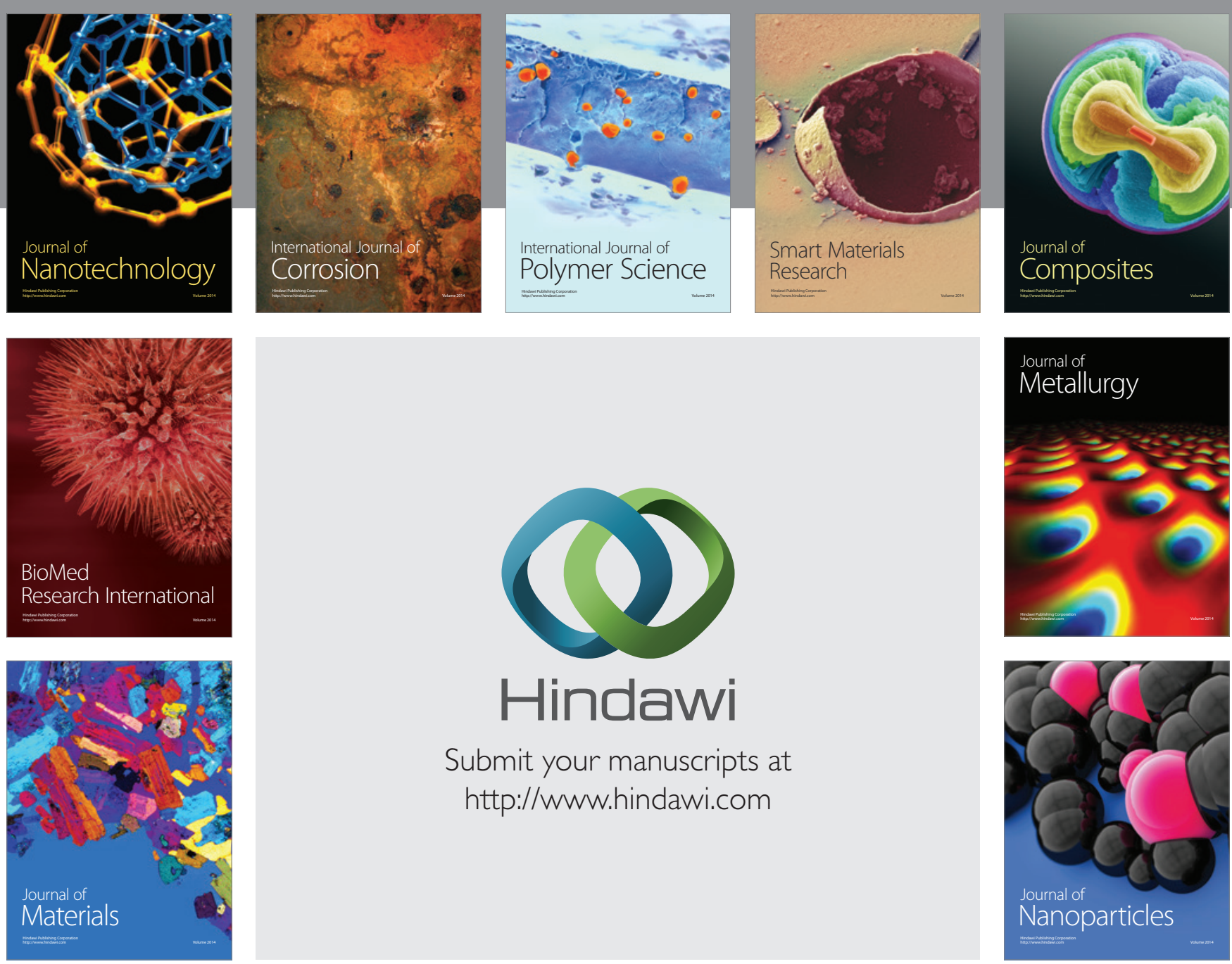

Submit your manuscripts at http://www.hindawi.com
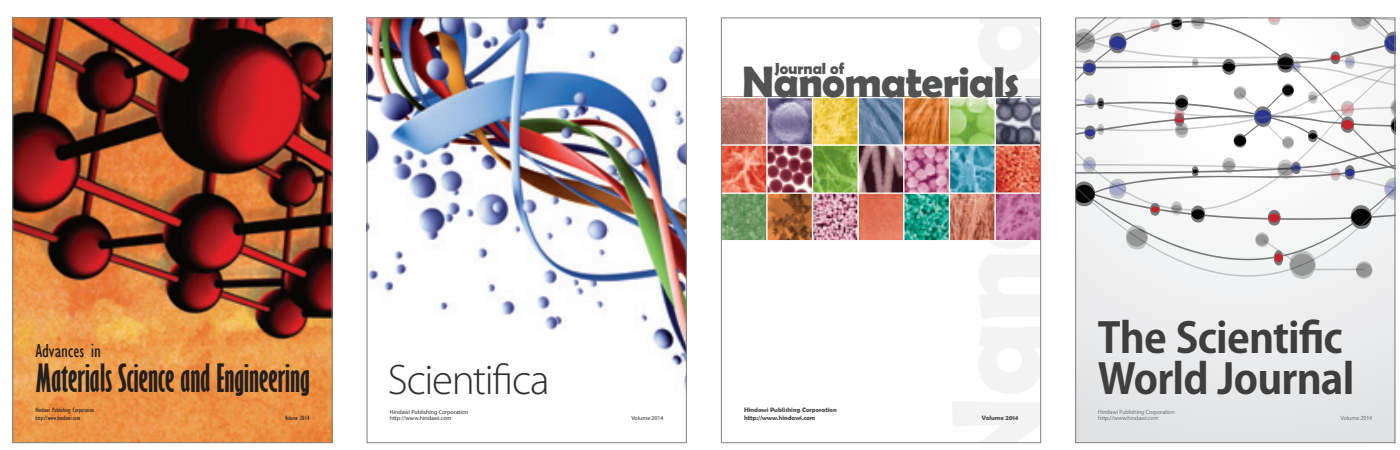

\section{The Scientific World Journal}
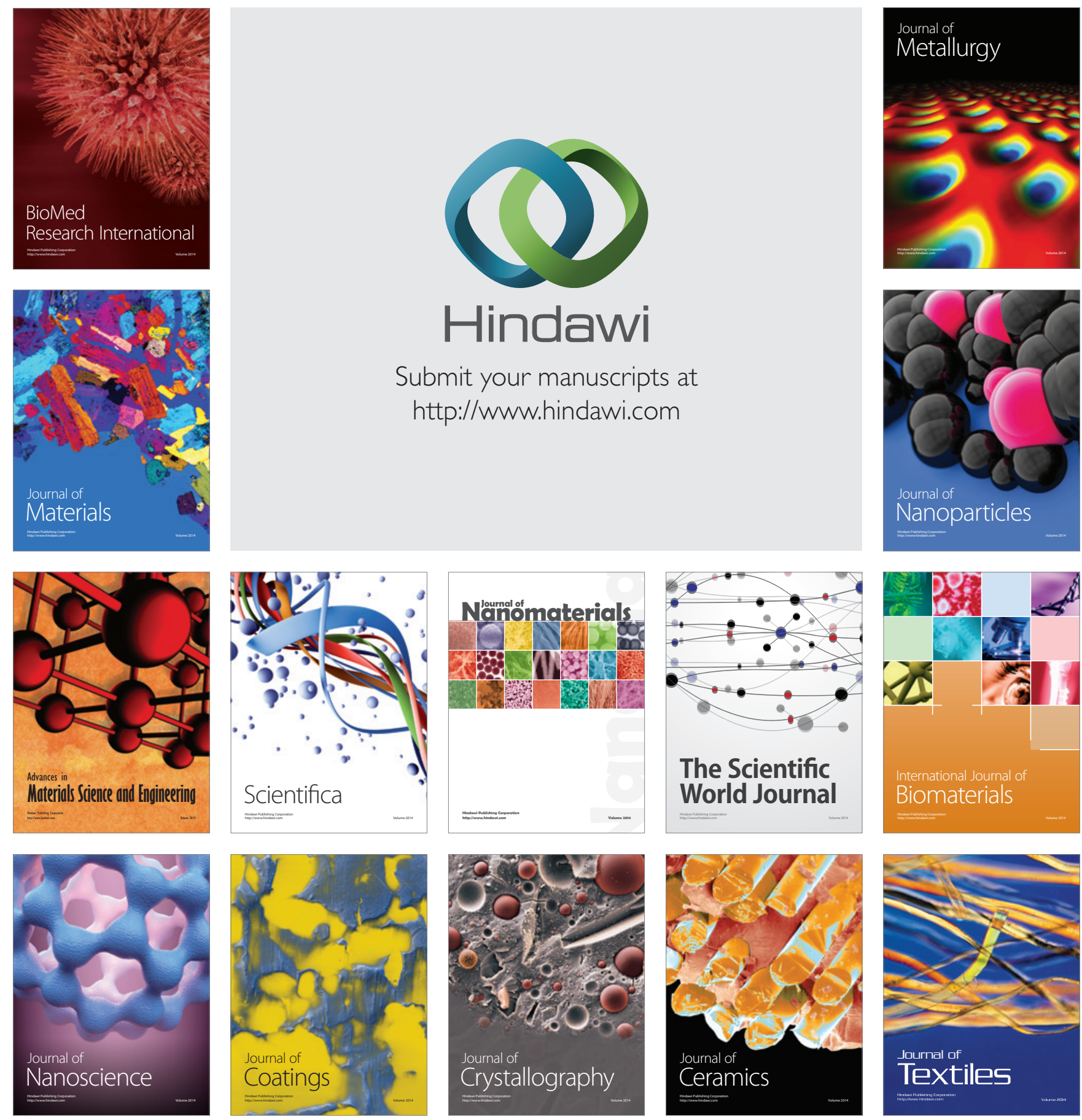